\title{
O SIGNIFICADO DA NUTRIÇÃO PARENTERAL PARA O CLIENTE NO CONTEXTO HOSPITALAR 1
}

THE MEANING OF PARENTERAL NUTRITION TO THE CLIENT IN HOSPITAL CONTEXT

Consuelo Helena Aires de Freitas Lopes ${ }^{2}$

RESUMO: A necessidade de compreender o significado da nutrição parenteral para o cliente no contexto hospitalar surgiu das nossas inquietações diante do cuidado de enfermagem. Realizaram-se observações participantes, entrevistas e anotações de campo junto a sete clientes hospitalizados, que se encontravam sob nutrição parenteral. O sentido das investigações foi centrado na indagação: como você está se sentindo com a nutrição parenteral?. Os dados foram analisados numa abordagem interacionista, mosirando as dificuldades enfrentadas pelos clientes na assistência hospitalar, como percebiam eles a nutrição parenteral e que significados eram atribuídos a essa terapêutica. $O$ estudo revelou os sentimentos, comportamentos e atitudes relacionados aos aspectos biológico, emocional e sócio-cultural do cliente, ligados à nutrição parenteral, demonstrando, também as limitações impostas ao cliente sob esse tratamento, bem como as dificuldades na assistência de enfermagem.

UNITERMOS: Significado - Enfermagem em nutrição parenteral - Contexto hospitalar

\section{TRAJETÓRIA JUNTO A CLIENTES EM NUTRIÇÃO PARENTERAL}

A decisão em estudar clientes no processo de nutrição parenteral decorreu da experiência em assisti-los por quase cinco anos. O despertar surgiu das discussões e recomendações sobre o assunto, quando na prática a assistência não se apresentava assim.

O trabalho em equipe multiprofissional no Hospital Universitário tinha exclusividade do enfermeiro no grupo e papel intensivo, proporcionando maior interação entre os membros da equipe e aproximação com a clientela.

A assistência especializada em nutrição parenteral estava muito voltada para o aspecto biológico e percebíamos a necessidade em assistir o cliente na sua totalidade. Passamos a questionar a qualidade da assistência. Parecia que, quanto mais especializada, mais se distanciava da totalidade do cliente como

\footnotetext{
${ }^{1}$ Dissertação de Mestrado em Enfermagem apresentada em 15 dez./95.na Universidade Federal do Ceará.

${ }^{2}$ Mestre em Enfermagem da UFC e Enfermeira do Instituto Dr. José Frota - Fortaleza. CE.

${ }^{3}$ Professora Doutora do Departamento de Enfermagem da UFC.
} 
"ser". Observávamos a presença do modelo médico-clinico que entende a doença como um processo biológico do indivíduo, além de isolar o homem do seu contexto social(Gelbcke,1992).

$\mathrm{Na}$ tentativa de nos aproximar do contexto cliente e família para melhor assistir, elaboramos algumas fichas e um histórico de enfermagem baseado nas necessidades humanas básicas e na terapia em foco, a fim de que os cuidados realizados fossem sistematizados, registrados, e que pudessem evoluir para uma assistência mais próxima de uma visão holística.

Durante a convivência com clientes e família, passamos a observar mais atentamente $\circ$ que diziam durante os cuidados, verificando mudanças de comportamento e sentimentos relacionados à nutrição parenteral.

Numa ocasião, ao assistir uma cliente idosa, durante a troca da nutrição parenteral, ela nos disse:

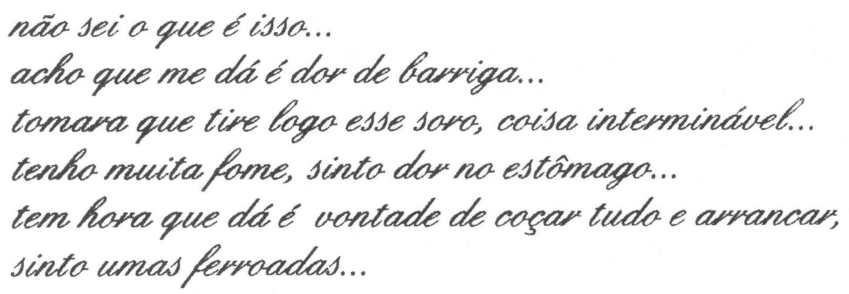

Essa fala foi durante um diálogo. Procuramos explicar a necessidade e o funcionamento do procedimento para que ela ficasse mais calma, pois estava muito alterada.

Essas experiências aconteciam com muita freqüência, motivo por que iniciamos a prática de ouvir mais atentamente os desabafos de clientes em nutrição parenteral.

\section{O SIGNIFICADO DA NP - UM ASPECTO QUE PARECE SER ESQUECIDO?}

Assistindo o cliente e a família no contexto hospitalar, o enfermeiro vivência particularidades das pessoas que, durante a convivência contínua, compartilham momentos de situação de doença, que geram a intimidade no próprio cuidar, estando, assim, susceptível perceber aspectos significativos surgentes no processo de interação. Segundo Haguette (1992), o sentido que as coisas têm emerge do processo de interação entre as pessoas, não sendo percebido como algo intrínseco ao "ser", seja como uma expressão dos elementos constituintes da "psykhe", mente, ou de organização psicológica.

Podemos considerar com atenção especial as pessoas que, na condição de hospitalizados, têm o seu cotidiano minuciosamente modificado como "ser". O cliente, quando se encontra em nutrição parenteral, sofre uma modificação inesperada no hábito da alimentação.

Cerezetti (1990) informa que a alimentação é muito mais do que a simples incorporação do material nutritivo, posto que possui um significado social e psicológico, porquanto envolve contato e calor humano e vem acompanhado de uma gama de afetos e simbolismos. Estando no hospital a vida social do cliente fica comprometida, pois esta pressupõe 0 ato de comer em comunidade. Em 
casa, na família, no aconchego, os cuidados na alimentação constituem de carinho, bemquerença, preocupação, amor, aceitação.

Portanto, para o cliente na ambiência hospitalar e em nutrição parenteral, onde às vezes se encontra até mesmo sem acompanhante, o processo nutritivo passa a ter outra contextualização.

Cerezetti (1990) acrescenta ainda que, para estes pacientes, o momento de alimentar-se sob estas condições não corresponde mais a um momento de integração e troca de afetos, pois passa a representar tensão, angústia e discriminação. Relata ainda que a nutrição parenteral não tem nenhuma carga de representação afetiva, não é desejada, mas imposta, somando-se a impossibilidade da alimentação como uma das fontes de diminuição da ansiedade pelo ato de mastigar e sugar.

Segundo Mead Apud Haguette (1992), a mente é concebida como um processo que se manifesta sempre que o indivíduo interage consigo, usando os símbolos significantes, sendo essa significância ou "sentidos" também de origem social.

Assim, sentimentos e comportamentos de clientes devem ser levados em consideração, o mesmo devendo acontecer relativamente à interação com os que fazem o contexto hospitalar, levando-se em conta, por fim, a participação nas atividades diárias diante da situação vivenciada.

\section{A NUTRIÇÃO PARENTERAL - Abordagem Específica}

O Suporte Nutricional Parenteral consiste na administração de aminoácidos, carboidratos, lipidios, vitaminas, eletrólitos e elementos traços por via endovenosa, sob a forma de solução constituída pela mistura desses elementos.

Surgiu para suprir as necessidades orgânicas do homem quando impossibilitado de alimentação por via natura!

Segundo ainda Waitzberg (1990), as categorias nas indicações são: préoperatório por doenças obstrutivas intestinais, complicações cirúrgicas pósoperatórias (fístulas intestinais, íleo prolongado e infecção peritoneal), estados pós-traumáticos (lesões múltiplas, queimaduras graves, infecção), desordens intestinais (vômitos crônicos e doença intestinal infecciosa), moléstia inflamatória intestinal (colite ulcerativa e doença de Crohn), insuficiências orgânicas (insuficiência hepática e renal) e condições pediátricas (prematuros, má formação congênita do trato gastrintestinal, diarréia crônica etc.).

Riella (1987) leciona que a nutrição parenteral pode substituir eficazmente, e por longos períodos o processo nutritivo natural. Para tanto, são necessários cuidados especiais e sistematizados, nas diversas fases do suporte nutricional.

Com respaldo na própria experiência, Vianna (1983) assegura que a infusão das soluções nutritivas deve ser feita por acesso venoso profundo em razão da alta osmolaridade das soluções. 
Burrie Henkemeyer apud Vianna (1983) recomendam as veias subclávias ${ }^{4}$ e jugular externa como as preferenciais. Vianna aduz que o emprego do cateter especial de silicone ${ }^{5}$ permite a instalação do túnel subcutâneo ${ }^{6}$.

O preparo da solução nutritiva deve ser efetuado em sala apropriada, com unidade de fluxo laminar ${ }^{7}$, contendo ante-sala para a paramentação devida, a fim de preservar as técnicas assépticas. O preparo é da competência do farmacêutico, seguindo o rigor asséptico e múltiplo conhecimento das possibilidades de incompatibilidade e instabilidade físico-químicas dos constituintes.

Quanto ao armazenamento das soluções preparadas, deve ser em refrigerador, entre $2^{\circ} \mathrm{C}$ e $4^{\circ} \mathrm{C}$, e protegidas da luz. Quando contêm eletrólitos e vitaminas, podem ser estocadas até 24 horas, e, quando sem adição de vitaminas, por até 72 horas. (Oliveira Apud Waitzberg, 1990).

$O$ êxito do tratamento nutricional depende da adequação entre $\circ$ valor calórico total administrado e o gasto energético total, sendo necessário o acompanhamento do estado nutricional do cliente em todo o percurso da terapêutica, utilizando-se dos diversos métodos aplicativos de avaliação nutricional.

Ao iniciar a nutrição parenteral, a etiologia do cliente deverá ser realizada através da coleta de dados, como: dados antropométricos (peso, altura, circunferência muscular do braço, prega cutânea) a serem avaliados diante de parâmetros ideais; dados bioquímicos (albumina sérica, transferrina sérica) para determinação das proteínas viscerais e contagem total dos linfócitos ${ }^{8}$ para avaliação da função imunitária; sinais e sintomas com aplicação do exame físico. (Riella, 1984). As necessidades calóricas poderão ser estimadas através da Equação de Harris-Benedict ${ }^{9}$.

A partir daí, um regime nutricional poderá ser traçado, segundo padrões determinantes que deverão ser obedecidos, onde a relação entre o total de calorias e o nitrogênio deverá ser de 120-180 calorias para 1 grama de nitrogênio (Kinney e Col. Apud Waitzberg, 1990); a proporção dos nutrientes

4 Veias subclavias - Infraclavicular e Supraclavicular.

5 Cateter de Silicone - Apresentam características de permanência prolongada.

${ }^{6}$ Túnel subcutâneo - Técnica de instalação do cateter em acesso venoso profundo com exteriorização de sua extremidade distal à distancia da inserção, protegendo o pacierite de infecções veiculadas pelo cateter. (Riella M. C. Suporte Nutricional Parenteral e Enteral. 1985.)

${ }^{7}$ Unidade de fluxo laminar é um dispositivo que ajuda a manter uma área asséptica. Os filtros evitam a entrada da contaminação que se gera no interior da zona e que possam ser removidos pelo ar, para partículas de 0,3 mícrons. (Veco do Brasil Indústria e Comércio LTDA.)

8 A contagem total dos linfócitos é calculada através do leucograma utilizando-se a contagem total de leucócitos e percentual de linfócitos, através da fórmula:

Linfócitos $=\%$ de linfócitos $\times$ contagem leucocitária / 100. Na desnutrição, a contagem linfocitária está entre 800-1200.( Riella, 1990).

9 Equação de Harris-Benedict correlaciona o gasto energético basal de um individuo normal determinado por calorimetria indireta com sua altura $(A$, em $\mathrm{cm})$, seu peso $(P /$ $\mathrm{Kg}$ ) e sua idade (I, em anos). Para homens, o GEB $=66+(13,7 \times \mathrm{P})+(5 \times A)-(6,8 \times$ I); e para mulheres, o GEB $=655+(9,6 \times P)+(1,7 \times A)-(4,7 \times \mathrm{I})$. (Riella, 1987) 
em relação ao valor calórico diário deverá estar em torno de $50-55 \%$ de hidrato de carbono, $12-15 \%$ de proteínas e $30-35 \%$ de lipídio. (Vianna, 1983).

Segundo Edmed Apud Riella (1984), a presença de anabolismo durante a nutrição pode ser verificada com eficácia através do balanço nitrogenado ${ }^{10}$, sendo, ainda, considerado o melhor método quantitativo e dinâmico na avaliação da terapêutica nutricional.

Polak (1983) menciona as complicações mais freqüentes da nutrição parenteral como mecânicas, infecciosas e metabólicas. As complicaçốes mecânicas (pneumotórax, hidrotórax, hemotórax, embolia gasosa e hematomas subclaviculares) decorrendo de falhas de ordem técnica; as complicações infecciosas devido à redução imunitária do paciente, resultante da própria flora microbiana ou agentes exógenos contaminantes, estando, também, relacionadas à manipulação do cateter venoso solução nutritiva e sistema de infusão venoso; e as complicações metabólicas podendo ser prevenidas com a adequada monitoração clínica da bioquímica do paciente através de reajustes equivalentes da solução nutritiva.

Acrescenta ainda a autora, o trabalho desenvolvido de forma integrada com equipe multidisciplinar e a prestação de uma assistência isenta de riscos exigem do enfermeiro conhecimento técnico, científico, humano e legal adequados.

Observamos o desenvolvimento técnico e científico no âmbito do suporte nutricional, com grande avanço tecnológico. No entanto, o que devemos considerar como marco primordial na área de suporte é o trabalho em equipe multiprofissional, que, sendo reconhecidamente importante pela assistência especializada a uma situação complexa e muito variável, mostra dedicação dos diversos profissionais, através de ações integradas, cada qual com a sua competência, mas com o pensamento único de assistir o cliente na superação do estado que se encontra.

$E$ sendo o enfermeiro integrante do trabalho em equipe, encontra-se presente em todo o processo do suporte nutricional, através de atividades assistenciais continuadas, vivenciando particularidades do cliente e família, no contexto em que se encontram e o mundo a que pertencem.

Nesse contexto é que resolvemos estudar o cliente em nutrição parenteral, fazendo a opção pela metodologia qualitativa e teoria interacionista, por intentarmos a compreensão de aspectos subjetivos dessa clientela

\section{DESCOBRINDO A FUNDAMENTAÇÃO TEÓRICO-METODOLÓGICA}

A opção pela metodologia qualitativa decorreu da busca em apreender o significado da nutrição parenteral para o cliente hospitalizado, os sentimentos e comportamentos vivenciando esta situação.

\footnotetext{
${ }^{10}$ Balanço nitrogenado baseia-se na excreção do nitrogênio uréico urinário durante o período de 24 horas. Quando a quantidade de nitrogênio (proteína) administrada no paciente é igual a quantidade excretada, dizemos que há equilíbrio; se a quantidade excretada for menor, dizemos que o balanço é positivo; e se for maior, dizemos que é negativo. (Riella, 1987)
} 
Identificamos 0 interacionismo simbólico com esse estudo por ser o significado o conceito central de investigação (Minayo,1994). As proposições da teoria existem a partir de fatos da vida cotidiana, permitindo uma instintiva investigação compreensiva de aspectos do comportamento (Haguette,1992).

O interacionismo simbólico mostra respeito pela natureza da vida e da conduta do grupo humano, estando na vida grupal a condição essencial para a consciência, mundo de objetos e construção de atitudes (Blumer, 1994)

\section{DESCREVENDO O REFERENCIAL INTERACIONISTA}

O interacionismo simbólico, como teoria e método, pode ser compreendido como uma vertente da etnometodologia ${ }^{11}$. Sua origem no fim do século XIX reúne estudos de Charles Horton Cooley (1864-1929), W. I. Thomas (1863 1947) e George Herbert Mead (1863 - 1931).

Mead fundamenta a teoria na descrição do comportamento humano, cujo dado principal é o ato social. (Haguette, 1992). O interacionismo simbólico conta com a última análise de três premissas simples criadas por Blumer, a partir dos pensamentos de Mead.

Os seres humanos agem em relação às coisas, tomando por base 0 significado que as coisas tem para ele;

O significado de tais coisas, às vezes, surge de uma interação social que a pessoa tem com seus iguais;

Esses significados são manipulados e modificados através de um processo interpretativo, usado pela pessoa para lidar com as coisas que ele encontra. (Blumer, 1994).

As coisas a que Blumer se refere incluem o que o ser humano pode observar em seu mundo físico. Conforme o significado que essas coisas têm para o ser humano, suas ações são dirigidas a essas coisas; portanto, tomado como base o significado dessas coisas (Blumer, 1994)

Para ele, o significado surge no processo de interação de duas pessoas, ou seja, o significado que uma coisa tem para uma pessoa cresce da forma pela qual as outras pessoas agem em relação a ele com relação a essa coisa. $O$ significado é formado dentro e através de atividades definidoras das pessoas quando interagem.

Quanto ao processo interpretativo, envolvido na ação da pessoa, derivado no contexto de interação social, o que ocorre é que a pessoa escolhe, checa, suspende, reagrupa e transforma o significado à luz da situação como um

\footnotetext{
${ }^{11}$ A etnometodologia estuda e analisa as atividades cotidianas dos membros de uma comunidade ou organização, procurando descobrir a forma como esses grupos as tornam visíveis, racionais e reportáveis, ou seja, como as consideram válidas, uma vez que o reflexo sobre o fenômeno é uma característica singular da ação (Haguette, 1992).
} 
processo formativo, onde os significados são usados e revisados como um instrumento para as diretrizes da ação (Blumer, 1994).

As regras e normas para as ações dos sujeitos são através da negociação de significados de sanções, de hierarquias e das próprias normas, sendo a partir da ordem social (Luz, 1994)

A interação simbólica, que envolve o processo de interpretação da ação, procura compreender o significado da ação de cada outro (Blumer, 1994).

Assim, pretendemos compreender o significado da nutrição parenteral para o cliente hospitalizado, diante da interação simbólica com a situação vivenciada e da ação deste cliente no contexto social.

\section{O CENÁRIO DO CLIENTE}

O cenário do cliente que se encontra em nutrição parenteral coincide com o ambiente físico terapêutico que já vem sendo vivido pelo cliente e família, pois o suporte nutricional parenteral consiste numa nova situação a ser aliada ao tratamento de base. Tem o objetivo de suprir as necessidades nutricionais do cliente naquele período crítico, oferecendo condições básicas para a reabilitação

Ao cotidiano terapêutico do cliente serão aderidas as particularidades do suporte nutricional parenteral, cuja existência se faz presente no seu corpo e imagem, de forma contínua e duradoura, sem interrupções, com permanência normalmente não inferior a duas semanas, podendo perdurar por meses ou até a vida toda, ficando na dependência do estado do cliente e resolutividade no tratamento.

Consiste no sistema contínuo de infusão (frasco de nutrição parenteral, equipo, bomba infusora, cateter e curativo), restrição total ou parcial da alimentação e cuidados intensivos continuados, entre estes: o controle rigoroso das funções vitais, da infusão da solução nutritiva e das demais infusões e eliminações, como também, atenção voltada para a mobilização e locomoção do cliente.

Podemos acrescentar a necessidade de cuidados especiais por ocasião da higienização, evidenciando que o cliente em nutrição parenteral passa a vivenciar nova situação a intensificar as dificuldades de satisfação das necessidades básicas.

Assim é que nasceu a necessidade de saber como estariam essas pessoas se sentindo na situação de doente hospitalizado sob esse expediente terapêutico parenteral.

\section{EMERGINDO A QUESTÃO NORTEADORA}

Durante a convivência com clientes em nutrição parenteral, conversávamos naturalmente sobre as necessidades do hospital, sobre o trabalho, familia, tratamento e outros assuntos de seu interesse. Observávamos que o cliente começava se expressar mais facilmente e participava mais livremente da conversa.

Por essa razão, nesse processo de interação, observávamos maior intimidade nos diálogos, mais confiança e liberdade deles para revelar os seus sentimentos. 
Em cada diálogo, através das falas e expressões, nós ficávamos mais certas de que, para cada um deles, existia um significado da nutrição parenteral, diante de cada situação que estava sendo vivida. Buscávamos o significado da nutrição parenteral através de uma questão que norteasse a situação que estava vivendo, individual e coletivamente. Sentimos emergir a questão nuclear do que estava sendo questionado:

\section{"Como você está se sentindo com a nutrição parenteral?"}

Acreditamos que essa questão envolve o mundo de objetos do cliente, possibilitando, assim, a compreensão do significado da nutrição parenteral durante a hospitalização, isto é as interpretações desse tratamento

\section{COLETANDO OS DADOS}

Resolvemos estudar adultos hospitalizados e em uso de nutrição parenteral, que estivessem conscientes, orientados e em condições de verbalizar suas necessidades, preocupações, sentimentos e atitudes.

Empregamos métodos qualitativos de coleta de dados representados nas observações livres, observações participantes e entrevistas semi-estruturadas.

Foram estudados clientes internados em enfermarias e que se encontravam a partir do terceiro dia de nutrição parenteral, por acreditarmos que esse período fosse suficiente para o cliente notificar as modificações orgânicas iniciais e conseqüentes e relatar seus pensamentos sobre elas.

Foi criado um instrumento de investigação contendo dados de identificação e observações do estado físico do cliente, com a utilização do prontuário e aplicação de técnicas para a realização do exame físico. Foram efetuadas coletas de dados referentes à situação familiar e hospitalização, que constituem o caminho para a questão norteadora: Como você está se sentindo com a nutrição parenteral?

Neste passo, foram investigadas as necessidades do cliente conforme suas colocações e levados em consideração os aspectos sentimentos, atitudes e significados.

A investigação foi desenvolvida com sete clientes hospitalizados em unidades clínicas e cirúrgicas em hospital de ensino e da rede municipal, no período de junho a setembro de 1995.

\section{ANALISANDO OS DADOS}

No caminhar para a fase de exploração do material coletado, as falas foram lidas exaustivamente na busca de elementos que expressassem significados latentes e manifestos.

E foi refletindo mediante a aparição dos sentidos, que utilizamos a codificação para organizar o material que, segundo Bardin (1977), corresponde a uma transformação dos dados brutos do texto através de recortes, agregação e enumeração em unidades, permitindo uma descrição exata das características pertinentes do conteúdo. 
Durante a organização do material, observamos convergências nas falas, de modo que resolvemos agrupá-las em unidades de registro, optando pela Análise Temática que, segundo Bardin (1977), consiste em descobrir os "núcleos de sentido" que compõem a comunicação e cuja presença ou freqüência de aparição pode significar alguma coisa para o objetivo analítico escolhido.

Mediante a extensão de significados surgidos, utilizamos o sistema de Categorização, com o agrupamento dos dados em Categorias e Subcategorias.

\section{OBSERVANDO E OUVINDO AS PESSOAS}

$$
\begin{aligned}
& \text {..... a fim de compreender as açöes das pessoas, é } \\
& \text { necessario identificar seu mundo dos objetos, o } \\
& \text { cenario, a textura das coisas que os confrontam. } \\
& \text { Herbert OBbumer }
\end{aligned}
$$

Esse excerto de Blumer faz-nos evocar as muitas vezes que nos aproximávamos dessas pessoas ao iniciarem a nutrição parenteral. Tínhamos como objetivo fazer esclarecimentos do tratamento, mostrando a importância para a sua recuperação e as diversas fases a serem enfrentadas, pois a sua aceitação e colaboração eram fatores imprescindiveis na realização da terapia.

Esses momentos nos faziam perceber a necessidade de abordar suas vidas, costumes, para que eu pudéssemos fazer comparações, facilitando, assim, sua compreensão $e$, quem sabe, despertar para a motivação $e$ credibilidade no que estava sendo feito visando a recuperação desses clientes.

$\mathrm{Na}$ tentativa de reunir dados que proporcionassem a compreensão de suas interpretações do que seja estar em nutrição parenteral, achamos por bem agrupar em categorias os dados que possibilitassem o delineamento do perfil dos clientes que serão apresentados a seguir.

\section{O CONTEXTO SÓCIO-ECONÔMICO E CULTURAL QUEM SÃO ELES?}

São duas mulheres e cinco homens, pertencentes à classe social desfavorecida do Estado do Ceará, procedentes do interior e litoral do Estado ou de bairros pobres da cidade de Fortaleza.

Para melhor compreendê-los no enfrentamento da situação de doente, vale a pena ver o que eles contam sobre suas vidas, seu cotidiano, o convívio familiar, expressando suas atividades naturais do dia-a-dia, revelando aspectos pertencentes à sua individualidade e à personalidade de cada qual. 


\section{QUANDO ELES FALAM DE...}

\section{- TRABALHO E RENDA}

O trabalho "versatilizado" e ao mesmo tempo homogêneo pelas opções do trabalho braçal é dependente do estado físico, que ora está comprometido como mostram os depoimentos:

...meu trabatho eva vendendo aurubs, ambulante. (Guedes)

...trahalhava num sitio, na raça, capinando, essas coisas (Oliveira)

- LAR, FAMÍLIA

Como forma elementar da vida cotidiana, "estar em casa" faz parte da inserção do homem no mundo conforme a sua vida individual (Kujawski -1991). $E$ esse homem que resolvemos estudar é o homem simples, na sua unidade e no sentido da palavra, é o trabalhador rural ou o operário que habita os bairros pobres das grandes cidades, estando o cotidiano muito ligado aos costumes tradicionais seguidos no meio rural. Podemos observar com clareza no depoimento de Guedes, que descreve os sentimentos e a maneira de reunir a familia.

..às veres a gente tem saudade dos filhos tudinho e não tá tudo, às veres junta um bocado, genro, neto, uma bagunga, tem fim de semana que junta três, quatro, fora das pessoas da gente, fora o final de semana, mais firn de semana vão passar là em casa...

Assim ele falava saudosamente e retratava a socialização familiar, que estava presente na sua lembrança. Berger (1991) nos lembra de que somente uma parte das experiências ficam retidas na consciência e que essas experiências são consolidadas na lembrança como entidades reconhecíveis.

\section{- LAZER}

..sóficar dentro de casa mesma, nãa tem pra onde sair, meu larer mesmo é só assistir televisana... (Gliveira)

... a meu divertimento em casa é misica, ter jornat, comer, tornar café, jogar uma firitia mais a minha espasa, genvo, fitha.... (Guedes)

Em sintonia com os seus modos de vida, convivência com a vizinhança e família, vivendo as coisa mais simples e elementares, parecem não estar conscientes do sentido de vida experimentado por eles. No seu entendimento, o lazer era passeios fora do alcance, das condições econômicas em que se colocavam.

É fácil, ainda, observar as vidas deles pertencentes a um cotidiano, que corresponde ao conceito do que eles são, quem são e para onde vão, enfim, o sentido de viver. 
Assim, ficamos a refletir como essas pessoas estão enfrentando essa situação de doente, eles que tiveram as suas vidas limitadas e passaram a ter outra conotação de vida.

De posse desse entendimento, adquirido no curso da vida e na literatura, procuramos percorrer todas as trajetórias dos nossos sujeitos, envolvendo desde o surgimento do mal, de como este é internalizado pelos clientes, até o processo de hospitalização e o conseqüente contexto em que vivem.

\title{
ENFRENTANDO A SITUAÇÃO DE DOENTE
}

\begin{abstract}
Nos devemos reconhecer que as atividades dos seres humanos consistem no enfrentamento de uma seqüencia de situascoes nas quais eles devem agir, e que suas açöes são construidas à base do que eles notam, de como eles avaliam e interpretam o que eles notam, e do tipo de linhas de ação rojetadas que eles mapeiam.
\end{abstract}

Herbert $\mathscr{B}$ lumer.

\section{COMPREENDENDO A DOENÇA}

Durante as entrevistas, dirigíamos nossas atenções para os relatos sobre a doença procurando ensejar-Ihes oportunidades para que revelassem como estavam compreendendo a doença, como havia sido causada, e que os levou a essa situação.

Silva, portadora de megaesôfago chagásico, relatava a origem deste mal da seguinte forma:

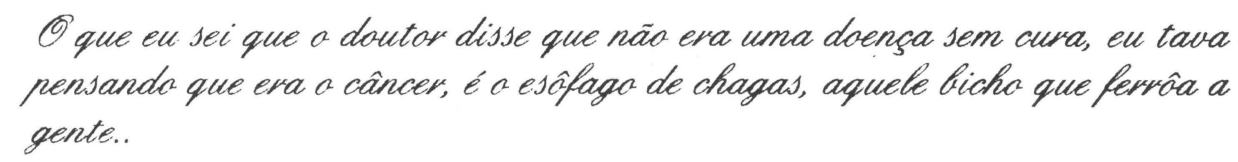

Embora tivesse insuficiente nível de instrução, ela sabia diferenciar uma doença maligna, incurável, de uma doença curável, causada por fator externo identificável, como é o caso da doença de Chagas. Na sua compreensão, sabia que era contraída pelo barbeiro" ${ }^{12}$, através da picada. Pensava estar com "o câncer" a julgar pela trajetória enfrentada durante a evolução do tratamento. Submeteu-se a cirurgia e a complicações que surgiram no pós-operatório. Vários procedimentos foram levados a efeitos, entre estes a nutrição parenteral. Entretanto, o médico havia dito que não era uma doença sem cura, o que significava credibilidade no médico e na cura.

\footnotetext{
12 Inseto hemíptero da família dos reduvídeos, subfamília dos triatomíneos. Maior de três dizem de espécies transmissoras da Doença de Chagas (bócio) são conhecidos no Brasil. No hinterland cearense é conhecido, entre outras denominações, pelo nome de "chupão".
} 


\section{RELEMBRANDO A TRAJETÓRIA DA INTERNAÇÃO}

Os participantes do estudo relembravam com detalhes a trajetória dos doentes, com os motivos que os levaram à internação. Caracterizaram, com clareza, o percurso das pessoas que procuram atendimento em hospitais da rede pública.

Esta situação está retratada no depoimento de Fernandes que se refere à forma como evoluiu seu estado, após a alta hospitalar, e como se sentia enfrentando esta situação:

$$
\begin{aligned}
& \text {... fui embora para a meu interior, eu emagreaí, começou a fastí e } \\
& \text { uma febre que só faltava me acabar, passei três meses farendo exame, } \\
& \text { fiquei bolando, aí vim prá cá... }
\end{aligned}
$$

Fernandes havia sido operada de colecistectomia em um outro hospital. Tinha recebido alta hospitalar, ainda com um dreno, e teve complicações na recuperação após a cirurgia, apresentando infecção cirúrgica.

Percebemos que a família de Fernandes estava ciente da infecção após a intervenção cirúrgica, mas não se mostrava interessada nas causas que levaram à infecção.

\section{PERCEBENDO O CONTEXTO HOSPITALAR}

Quando indagávamos como estava sendo a assistência recebida no hospital, diziam que estava boa, demonstrando estar satisfeitos. Observamos o mesmo sentido nos depoimentos de Silva, Guedes, Fernandes e Nogueira, e convergimos para a única frase:

$$
\begin{aligned}
& \text {... a assistência tá boa graças a Deus, acho born aqui, tudo ótimo... (Silua, } \\
& \text { Guedes, Fernandes e Nogueira) }
\end{aligned}
$$

Embora eles demonstrassem gratidão, percebiam também as dificuldades na assistência, aceitando e compreendendo. Apesar dos sentimentos, comportamento e atitudes que apresentavam diante das falhas percebidas na assistência hospitalar, eles reconheciam 0 atendimento contínuo da enfermagem às suas solicitações, estando sempre presente durante o processo de assistência.

\section{O CUIDADO}

No entendimento de Waldow (1995), o cuidar é uma expressão de humanidade, necessário ao desenvolvimento e realização do ser humano, não devendo ser considerado como privilégio ou característica da enfermagem.

No entanto, a enfermagem tem maior aproximação com o cliente, estando disponível continuamente, assistindo diretamente as necessidades do cliente e família, compartilhando em todos os momentos. Tornando-se evidente, atribuir - cuidado como a assistência de enfermagem que os clientes estavam percebendo. 
O cliente em nutrição parenteral permanece mais no leito, pelas limitações no deambular, mobilizar e, até mesmo, em autocuidar-se, ficando mais dependentes da assistência de enfermagem.

Dentre as dificuldades que a enfermagem enfrenta na assistência, é relevante pinçar a carência de pessoal de enfermagem, relacionado com o número de clientes, mesmo que não se tome em consideração $\circ$ grau de dependência dos clientes a esses profissionais.

$\mathrm{Na}$ forma como Fernandes, por exemplo, expressa esse cuidado de enfermagem, parece haver, além do mero relato, o reconhecimento:

... a enfermeira me leva com todo trabalho, ela me levou com isso ai lbomba infusara/ para o banheiro, no outro dia, não me levaram näo...

Ela demonstrava o reconhecimento da dificuldade em levá-la ao banheiro para o banho, sabendo que isto não acontecia todos os dias. Portanto, a higiene estava sendo realizada mais no leito.

Como sabemos, o banho no leito parece não satisfazer o cliente quando ele tem disposição para tomar banho de chuveiro ou mesmo de aspersão. leito:

Assim, verifiquemos como Nogueira se sentia quando tomava banho no

...é muito ruim tomar banho deitadr porque é frio demais.

O cliente em NP, quando entra em estado de anabolismo, ganhando energia e calorias, sente-se mais recuperado, com disposição, necessitado de retomar as atividades que desenvolvia sozinho, o autocuidado. Necessita de deambulação para se evitar complicações vasculares, cutânea, muscular, articular, pulmonar e outras (Polak, 1983). Sendo tal impossivel, ele precisa de mobilização ativa no leito, ou fora deste, desde que o organismo seja mantido em atividade.

\section{O ACOMPANHANTE}

Demonstrando grande necessidade, o cliente identifica o acompanhante não somente como uma pessoa familiar para the fazer companhia, mas, sobretudo, como pessoa para ajudar no atendimento das necessidades biológicas básicas. Esse asserto ficou demonstrado nos depoimentos de Silva, Oliveira, Costa e Freire, que agrupamos assim:

.... a acmparharte tem me ajudado bastante, tem me levantado, sentado, botado spansteira, dado banha, trocasto as pancs. ISibua, Gliveira, Gasta e. Freirel

O acompanhante, por ser uma pessoa permanente com o cliente, poderá muito contribuir, tanto para a enfermagem como para o cliente, mas, antes de tudo, precisaria que a enfermagem o orientasse para os possíveis cuidados a serem prestados, mesmo assim, ficando a enfermagem com a responsabilidade de todos os cuidados.

Silva, Costa e Freire apresentaram nos depoimentos o prazer da companhia de uma pessoa conhecida, que, com o mesmo sentido, agrupamos da seguinte forma: 
.... a gente tá conversands, peryuntarls unse coisa e outra, de noite agente conversas, passa mais a noitl...

A conversa será, talvez, a ocupação mais deleitosa e fecunda do cotidiano, permitindo o reconhecimento, sem reservas, das pessoas entre si, e, ao contrário de ser perda de tempo como pode parecer, é ganho, porque a freqüência da conversa reforça seu poder gerador da realidade (Kujawski, 1991). E como forma de passar o tempo, conversando, relembrando as lembranças, eles se mostram mais compreensivos e satisfeitos.

\section{A VISITA}

Sendo sempre um momento de reencontro para a família e amigos, a visita acontece no período da tarde. Longe do acompanhamento médico e das decisões no tratamento, que geralmente ocorrem no periodo da manhã, quando da visita médica os visitantes procuram a enfermagem, sempre presente, para esclarecimentos quanto à situação do cliente.

Nem sempre, porém, ficam satisfeitos. Muitas vezes, a própria enfermagem não é participada quanto às decisões tomadas para o tratamento do cliente. A familia deve ser orientada, a procurar as informações que se fizerem necessárias, para o conhecimento da situação do cliente.

Contudo, a satisfação é sempre vista e relatada por eles. Guedes menciona a visita como momento de dialogar:

. quanto mais visita mais acho methor ainda, de mancira prá dialogar com as pessoas... (Guedes)

É de se observar, aqui, a necessidade de Guedes de conversar com as pessoas pertencentes ao seu mundo de objetos, a interação com os amigos e pessoas da família, demonstrando conforto emocional e maneira de se fortalecer como pessoa.

\section{PERCEBENDO A NUTRIÇÃO PARENTERAL}

Freire, Silva, Guedes, Oliveira e Nogueira faziam suas interpretações relacionadas à NP. A maneira como percebiam a NP está materializada no seguinte:

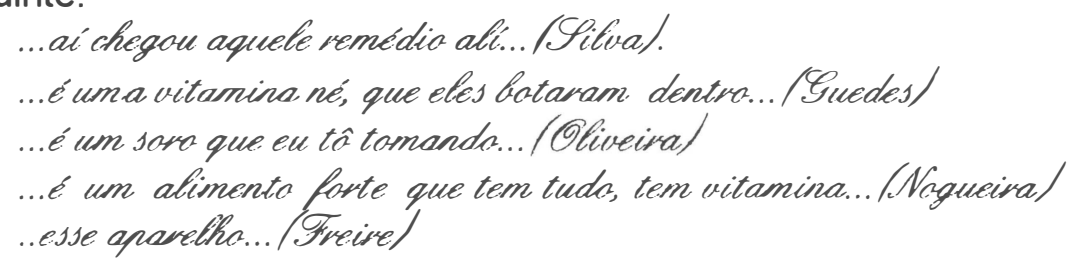

Remédio, vitamina, soro, alimento e aparelho foram as formas como eles interpretaram a NP. O significado era baseado na forma como as pessoas definiam a NP para eles. 
Portanto, a natureza da nutrição parenteral dependia da orientação deles, de como as pessoas referiam a NP. Assim, os significados foram formados pelas definições que as pessoas faziam para eles, de como definiam a NP no processo de interação.

\section{O (DES)CONHECIMENTO}

...eu náa sei nada sobve ele...

disso aí.. isso aí..

Assim, todos eles responderam quando perguntávamos o que sabiam sobre "esse tratamento". Usamos essa expressão, em vez de Nutrição Parenteral, para que percebêssemos se conheciam a denominação do tratamento.

Como não conheciam o nome da nutrição parenteral, dizíamos textualmente a denominação. Notamos, porém, que se intimidavam nas suas respostas diante do termo científico.

Eles respondiam olhando para a bomba infusora, como algo desconhecido. Constatamos que o desconhecimento se relacionava com a funcionalidade da bomba infusora, aliado ao sistema de infusão, representando uma tecnologia desconhecida.

Posteriormente, no decorrer da entrevista, quando eles ficavam mais familiarizados com o nosso diálogo, mostravam o que sabiam da NP, o que podemos ver numa única frase:

... disseram que era alimentação...

Esta foi a resposta de todos eles, quando indagamos a finalidade "desse tratamento", o que nos leva a intuir que eles não estavam interpretando a NP como alimentação.

Conquanto, suas respostas fossem baseadas no que the diziam, eles não estavam indicando para si a NP como alimentação. As observações que faziam da NP eram, segundo a forma como estavam vendo, diferentes da maneira de alimentação que conheciam, que possuiam como representação.

\section{ALIMENTAÇÃO}

Como alimentação, era a utilidade que as pessoas diziam ter a NP para eles. No entanto, demonstravam as interpretações baseadas no que estavam percebendo.

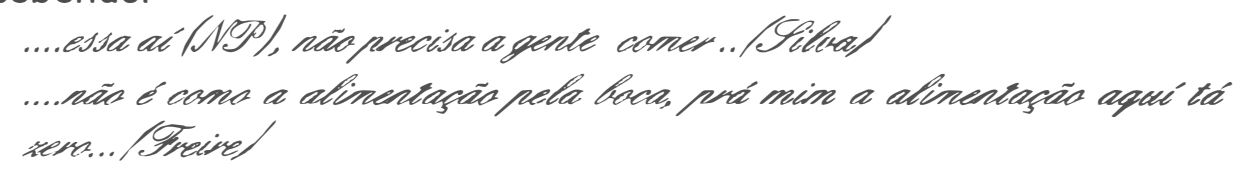

Silva deixa clara a dispensa do ato de comer, e Freire, comparando a NP com alimentação oral, considera que o seu organismo não estava sendo alimentado. 


\section{A CREDIBILIDADE}

Os depoimentos de Guedes e Costa mostram que acreditavam na NP pela forma como estava se apresentando para eles, como tratamento que estava sendo realizado na sua doença.

..isso aqui (NDP) tá sevvindo para farrer a minha alimentaçás, mais não tá servindo de alimentasão... (Guedes)

...é como tá comendo norrnal, mesmo porque a gente nás tá se alimentando né.. (Costa)

É lícito concluir que esses depoimentos deixam mais claro ainda o fato de eles não interpretarem a NP como alimentação. Compreendem que a NP está sendo utilizada como nutrição no organismo, mas desconhecem a forma de expressar essa diferença.

A alimentação significa o "ato de comer", cercada de todos os rituais e sentimentos vividos na forma de cada um. A escolha dos alimentos, a forma de prepará-los, estão de acordo com a representação do mundo das pessoas (Kujawski, 1991). E a cultura do almoço e jantar, representando as grandes refeições do dia, significa a consideração de estarem sendo bem alimentados.

\section{NO ESPAÇO - TEMPORAL}

...tá com dore dias ou mais que eu tâ nisse aqui (com a NPP), só comendo isso aqui, passando fome... (Freire)

Freire demonstrava sofrimento, remetendendo-se ao tempo em que estava em NP, correspondente ao período em que estava sem comer, "passando fome". Era assim que se sentia, com fome.

\section{SENTIMENTOS COM A NUTRIÇÃO PARENTERAL}

Observando os sentimentos com a NP, relacionados ao aspecto biológico, percebe-se nos depoimentos de Silva, Guedes, Fernandes, Oliveira e Nogueira, o modo como se sentiam após terem iniciado a NP:

...eu tô bern mehor com ela (NDP) do que antes, a gente se sente mais confortável por dentro, mais apsiadn, se a gente näs sente a barriga cheia, mais sente que está se fortificando...

Observando, ainda, os sentimentos relacionados ao aspecto biológico ligados à nutrição parenteral, ocorreu a presença da sensação de fome, relatada por Guedes, Oliveira, Nogueira e Freire, a seguir.

...eu me sinto com fome, dixem que a gente näo passa fome, mais eu sinto. Al minha vontade mesmo, é de tomar suco, água, comer frutas, porque a 
alimentasäo pesada, eles nãs oferece. muit a vontade de comera que for preciso, me alimenta, a gente quands vê a pessoa que se abimenta normal pela boca, a gente sente aquela vontade.....

Os depoimentos clarificam suficientemente as definições propostas para ele pela equipe de saúde, configuradas no conceito de que a NP é alimentação. No entanto, ele sente fome, desejo de comer e tem outra definição de alimentação. Interpreta que está passando fome, pois, para ele, só valem "almoço e jantar"os repastos principais do dia.

É simples tirarmos a conclusão de que o medo que sentiam estava relacionado à possibilidade de eles não conseguirem mais deglutir. Há muito tempo não deglutiam.

Este receio, psicologicamente procedente, foi revelado no melancólico relato de Freire:

...é um negócio meia triste, não tem coisa mais triste do que a pessoa näs se alimentar pela boca, nãs tem não...

Lágrimas Ihe caíam. Estava muito emocionado e com uma tristeza intensa pelo fato de não estar se alimentando. Sentia-se maltratado e castigado. Queria se operar logo para que esse sofrimento terminasse.

Alguns relataram sentimentos relacionados ao aspecto sócio-cultural, ligado à alimentação. Silva, Guedes e Oliveira, falam, com palavras diferentes, a mesma coisa, configurada no trecho seguinte:

.... as veres tenho vontade de comer assim wna besteira, näs que eu tenho fome, qualquer coisa, uma masä, chupar una havajia, às coisas mesmo.as minhas comidas doidas em casa, eu gosto de came de poros bem gordas, com pás de milho, um peixe com leite de côco, a que eu for comer na mesa, mais nãs aqui, que eu abusei...

A vontade que eles sentiam de comer alguma coisa não estava sendo interpretada por eles como causada pela fome. Estavam referindo o prazer de comer alguma coisa, ou, até mesmo, o desejo de comer as "comidas", que eram consideradas muito saborosas.

\section{AÇÃO LIMITADA}

...se eu ia comer outra coisa, eu não como nem una bolachinha que eu gastava, hoje em dia eu nás posso mais, eu tenhs vontade de beber kgua e náa bebo, eu andava por todo canto aqui, agora depois que eu tô com essa maquina, näs posso is as banheiro me baubear, tomar um banhs,...é estou amarrada de um lado e do outro, tô ligado, e náa adianta sair doqui ligada.../Silva, Guedes, Fernandes, Gliveira, Nogueiva, Gasta e Freire) 
Assim, todos eles se sentiam com as ações limitadas, relacionando com a nutrição parenteral. A liberdade de agir encontrava-se limitada e restrita. Algumas vezes não tinham escolha para mover-se locomover-se e eliminar, por exemplo. Sentiam-se incapacitados para satisfazer as necessidades básicas. Luz (1993) menciona que são as ações dos outros que determinam a ordem social naquele contexto institucional, o próprio sujeito não redefine as normas e regras de uma situação.

\section{REFLETINDO O SIGNIFICADO}

Refletir a significação da nutrição parenteral para o cliente no contexto hospitalar significa também reflexionar a enfermagem no cuidado, circunstancialmente, em nutrição parenteral. $O$ significado vem acompanhado do tratamento da doença e procedimentos terapêuticos, estando a nutrição parenteral incluída neste contexto.

Os sentimentos, comportamentos e atitudes observados diante das limitações impostas na nutrição parenteral e tratamento da doença, das dificuldades encontradas no atendimento das necessidades, demonstrava conflitos no Eu que emergiam do processo de interação social.

Eles definiam para si as necessidades, o significado do cuidado, interpretando e construindo suas ações.

As interpretações, surgindo da interação social - cliente e família com a equipe de enfermagem - mostram o cuidado a partir da interação humana, da participação intersubjetiva com o cliente e a família. $O$ entendimento entre o cliente, família e equipe de enfermagem resulta na assistência qualificada.

E relembrando a questão: "Como você está se sentindo com a nutrição parenteral"?, que norteou os significados da nutrição parenteral na situação vivenciada, pudemos apreender o cliente como inseparável do mundo de objetos e ambiente presente, co-participando das diversas situações vivida por ele, interpretando e criando as ações. Ficando evidente, a necessidade do cuidar sob uma visão holística, levando-se em consideração as crenças, valores, educação, situação econômica e família.

Apreendemos também a importância em mostrar para o cliente e família a necessidade da participação no tratamento de nutrição parenteral.

Proporcionando adaptação ao ambiente e evitando a inibição no conhecimento da nutrição parenteral, fatores que desencadeiam dificuldades no bem-estar e senso de participação.

Assim, cliente e família devem ser treinados e orientados em alguns cuidados com a nutrição parenteral, visando facilitar a mobilização, locomoção com a bomba infusora e sistema de infusão, a fim de que possam agir seguramente dentro das limitações.

Para tanto, sem a pretensão de exaurir o assunto, mas com a perspectiva de olhar o homem como um ser aberto e ator de suas ações, intercambiando 
simultaneamente com o ambiente e seus valores, elaboramos um diagrama mostrando os significados manifestados na interação social.

\title{
SIGNIFICADOS VIVENCIADOS PELO CLIENTE NO PROCESSO DE NUTRIÇÃO PARENTERAL
}

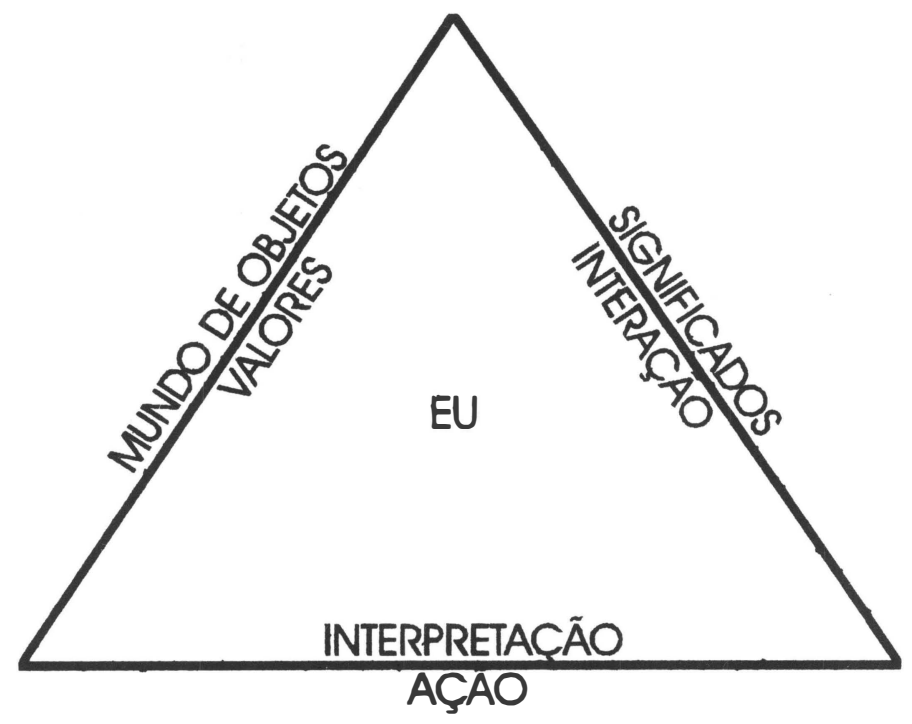

Almejar sensibilidade no cuidado de enfermagem, no âmbito da nutrição parenteral, e tentar compreender o cliente como uma pessoa no seu mundo de objetos, enfrentando a hospitalização e a nutrição parenteral, dentre os procedimentos existentes. É perceber os sentimentos e comportamentos, diante das dificuldades na assistência. É repensar e fazer o cuidado, voltando-se para a orientação e co-participação com o cliente e sua família.

\begin{abstract}
The need to understand the meaning of parenteral nutrition to the client in hospital context has come from my personal questioning on nursing care. Participative observations have been made as well as interviews and diligences with seven clients in hospital, who have been having parental nutrition. These information have been analysed through interactive approach, showing the situation faced by patients who have hospital assistance; how they say parental nutrition within this context; and what meaning has been given to it. This study revealed feelings, behaviours and attitudes related to the biological, emotional and social cultural aspects of the patient. All of them have been linked to parental nutrition. The limits faced by parental nutrition and its obstacles in the nursing assistance were finally understood.
\end{abstract}

KEYWORDS: Meaning - Parental nutrition nursing - Hospital context. 


\section{REFERÊNCIAS BIBLIOGRÁFICAS}

1. BARDIN, L. Análise de Conteúdo. Lisboa: Edições 70, 1977. 225 p.

2. BERGER,P. LUCKMAN,T. A construção social da realidade. 9 ed. Rio de Janeiro, Petrópolis: Vozes, 1991.

3. BLUMER, H. Symbolic Interacionism Perspective and Method. Califórnia: Prentice BODINSKI, L.H. The nurse's guide to diet therapy. Trad. SAMBAQUY, C. et al. New York: John Wiley and Sons, 1988.

4. CEREZETTI, C. C. N. "Aspectos Psicológicos do paciente com alimentação parenteral". In: WAITZBERG, D.L. Nutrição Enteral e Parenteral na Prática Clínica. Rio de Janeiro: Atheneu, 1990.

5. GELBCKE, F. L. "Processo Saúde Doença: a procura da essência". Texto Contexto Enf. Florianópolis, v.1, n.2, p. 4 - 9, jul/dez/1992.

6. HAGUETTE,T.M.F. Metodologias Qualitativas na Sociologia. 3 ed. Petrópolis: Vozes, 1992.

7. KUJAWSKI, G.M. A Crise do Século XX. São Paulo: Ática, 1991.

8. LUZ, M T. "O interacionismo simbólico: breve exposição de uma corrente acionalista em ciências sociais." In: CARVALHO, M.C.B. Teorias da Ação em Debate. São Paulo: Cortez FAPESP: Instituto de Estudos Especiais, PUC, 1993.

9. MINAYO, M.C.S. O desafio do conhecimento: Pesquisa qualitativa em saúde. Rio de Janeiro: ABRASCO - HUCITEC, 1992.

10. OLIVEIRA,M. F. et al. "O preparo das soluções de Nutrição Parenteral Total. In: WAITZBERG,D.L. Nutrição Enteral e Parenteral na Prática Clínica. Rio de Janeiro: Atheneu, 1990. p.247-251.

11. POLACK, Y.N.S. Enfermagem e Nutrição Parenteral. 2 ed. Rio de Janeiro: Cultura Médica, 1983.

12. RIELLA, M. C. Suporte Nutricional Parenteral e Enteral. Rio de Janeiro: Guanabara Koogan. 1987.

13. VIANNA,R, LAMEU,E., MAIA,F. et al Manual de Suporte Nutricional Parenteral e Enteral do Hospital Universitário da Universidade Federal do Rio de Janeiro. Rio de Janeiro: Cultura Médica, 1983.

14. WAITZBERG, D.L. Nutrição Enteral e Parenteral na Prática Clínica. Rio de Janeiro: Atheneu, 1990.

15. WALDOW,V.R; LOPES,M.J.M; MEYER,D.E. Maneiras de cuidar. Maneiras de ensinar. Porto Alegre, Artes Médicas, 1995. 